\title{
Caspofungin primes the immune response of the larvae of Galleria mellonella and induces a non-specific antimicrobial response
}

Correspondence

Kevin Kavanagh

kevin.kavanagh@nuim.ie

Received 25 August 2010

Accepted 12 October 2010

\author{
Judy Kelly and Kevin Kavanagh
}

Medical Mycology Unit, Department of Biology, National Institute for Cellular Biotechnology, NUI Maynooth, County Kildare, Ireland

\begin{abstract}
The echinocandins (e.g. caspofungin) function by inhibiting the synthesis of $1,3-\beta$-glucan in the fungal cell wall. While the potent antifungal activity of caspofungin has been well characterized in mammals, this study investigated the in vivo antifungal effect of caspofungin using larvae of the insect Galleria mellonella. Caspofungin was successful in increasing the survival of larvae that were inoculated with Candida albicans $1 \mathrm{~h}$ before the drug was administered, particularly when a concentration of $0.19 \mu \mathrm{g} \mathrm{ml}^{-1}$ was used. Pre-injecting larvae with caspofungin also increased their survival when they were inoculated with either Staphylococcus aureus or C. albicans. Caspofungin administration resulted in an increase in the number of circulating immune cells (haemocytes), an increase in the expression of the genes encoding IMPI and transferrin, and an increase in the expression of a number of proteins (identified by liquid chromatography-mass spectrometry) some of which have immune functions. This work indicates that administration of caspofungin can increase the survival of infected G. mellonella larvae, and this is due to the antifungal properties of caspofungin and also to the ability of caspofungin to prime the insect's immune response.
\end{abstract}

\section{INTRODUCTION}

Interest in using insects as alternative models to mammals for the in vivo screening of novel antimicrobial drugs (Hamamoto et al., 2004, 2009) or for assessing the virulence of microbial pathogens (Brennan et al., 2002; Lionakis \& Kontoyiannis, 2005) has been growing for a number of years, since the immune response of insects shares a high level of homology with the innate immune response of mammals (Kavanagh \& Reeves, 2004). Insect models of microbial infections have been employed to investigate the antimicrobial properties of drugs (Lionakis \& Kontoyiannis, 2005; Johny et al., 2007) and offer many advantages over the use of mammals (Kavanagh \& Reeves, 2004). Larvae of the Greater Wax Moth, Galleria mellonella, have been used to evaluate the antifungal activity of amphotericin B, flucytosine and fluconazole following infection with Cryptococcus neoformans (Mylonakis et al., 2005), while silkworms have also been used to investigate the activity of commonly used antimicrobials including the antifungal fluconazole (Hamamoto et al., 2004).

Larvae of G. mellonella are inexpensive to purchase, results can be obtained within $48 \mathrm{~h}$ and a large number of insects

Abbreviations: 2D, two dimensional; AMP, antimicrobial peptide; $\mathrm{JH}$, juvenile hormone; JHBP, juvenile hormone binding protein; LC-MS, liquid chromatography-mass spectrometry; NUI, National University of Ireland. can be inoculated in a short period of time (Cotter et al., 2000). G. mellonella larvae have been used to assess the pathogenicity of mutants of Pseudomonas aeruginosa and a correlation has been established between their virulence in G. mellonella and in mice (Dunphy et al., 1986; Jander et al., 2000). Similarly a correlation between the virulence of Candida albicans mutants in G. mellonella and mice has been demonstrated (Brennan et al., 2002), and the larval model has been used to allow the determination of the virulence of relatively 'weak' fungal pathogens (Bergin et al., 2003). In addition, G. mellonella larvae have been established as a good model for studying the virulence of Cryptococcus neoformans (Mylonakis et al., 2005).

The insect immune system bears a number of structural and functional similarities to the innate immune response of mammals (Zhao \& Kanost, 1996; Rock et al., 1998; Wittwer et al., 1999). The cuticle of the insect serves a function analogous to the skin in mammals and provides a barrier to infection. The haemolymph of insects is contained within the body cavity (haemocoel) and serves a function comparable to blood, where it transports nutrients, waste products and signal molecules (Matha \& Acek, 1984). Haemolymph contains circulating immune cells (haemocytes) that are capable of immobilizing and killing invading microbes (Lavine \& Strand, 2002). The humoral element of the insect immune response consists of the processes of melanization, haemolymph clotting, 
antimicrobial peptide (AMP) synthesis and wound healing (Kavanagh \& Reeves, 2004). AMPs are released from haemocytes, other cells and organs into the haemolymph, where they attack components of the bacterial and fungal cell membrane and wall (Ratcliffe, 1985).

The echinocandins are a relatively new group of antifungal agents and caspofungin was the first of this group to be licensed for use (Kartsonis et al., 2003). Echinocandins show potent activity against the yeast $C$. albicans and are unique in their mode of action by targeting the biosynthesis of the fungal cell wall. In particular, echinocandins inhibit the synthesis of $1,3-\beta$-glucan, the major polymer of the fungal cell wall (Eggimann et al., 2003). Since caspofungin targets the synthesis of the cell wall, a structure not found in mammalian cells, minimal toxicities are observed in humans, and excellent in vivo activity has been observed in patients (Petraitiene et al., 2002).

This study examined the in vivo activity of caspofungin in larvae of the insect G. mellonella. The objective of this work was to determine whether the survival of larvae administered caspofungin was due to the antifungal activity of the drug alone or to the induction of a protective immune response by the drug in the treated larvae.

\section{METHODS}

Assessment of the effect of caspofungin on the viability of $G$ mellonella inoculated with C. albicans or Staphylococcus aureus. Sixth instar larvae of G. mellonella (the greater wax moth, which belongs to order Lepidoptera, family Pyralidae) were obtained from The Mealworm Company (Sheffield, England) and stored in wood shavings in the dark at $15{ }^{\circ} \mathrm{C}$. Larvae chosen for experiments weighed between 0.2 and $0.4 \mathrm{~g}$. Ten healthy larvae were placed in sterile $9 \mathrm{~cm}$ Petri dishes containing a sheet of Whatman filter paper.

C. albicans strain MEN (a gift from Professor D. Kerridge, University of Cambridge, Cambridge, England) was grown to early stationary phase $\left(1-2 \times 10^{8} \mathrm{ml}^{-1}\right)$ in YEPD liquid [2\%, w/v, glucose; (SigmaAldrich), $2 \%$, w/v, bacteriological peptone (Oxoid) and $1 \%$, w/v, yeast extract (Scharlau Chemie)] in an orbital shaker (200 r.p.m.) at $30{ }^{\circ} \mathrm{C}$. Cells were harvested and washed in PBS (Sigma-Aldrich), and resuspended in PBS at cell densities of either $5 \times 10^{5}$ or $1 \times 10^{6}$ cells per $20 \mu \mathrm{l}$. Larvae were inoculated through the last left pro-leg into the haemocoel with a volume of $20 \mu \mathrm{l}$ using a Myjector syringe (Terumo Europe) and placed at $30{ }^{\circ} \mathrm{C}$ in the dark. All experiments included a control that consisted of larvae injected with sterile PBS $(20 \mu \mathrm{l})$ and/ or untouched larvae.

For the assessment of the in vivo antifungal activity of caspofungin, larvae of G. mellonella were inoculated with C. albicans as described, and $1 \mathrm{~h}$ post-inoculation were further injected with a $20 \mu \mathrm{l}$ volume of caspofungin at concentrations of $0.19,0.095$ or $0.0475 \mu \mathrm{g} \mathrm{ml}$ (Merck) or PBS, and placed at $30{ }^{\circ} \mathrm{C}$ for 24,48 and $72 \mathrm{~h}$. The concentrations of caspofungin used here relate to the $\mathrm{MIC}_{90}, 1 / 2$ $\mathrm{MIC}_{90}$ and $1 / 4 \mathrm{MIC}_{90}$ values for C. albicans, respectively (Kelly et al., 2009).

Alternatively, larvae were injected with PBS or caspofungin (as above), placed at $30{ }^{\circ} \mathrm{C}$ for $24 \mathrm{~h}$ and subsequently inoculated with a $20 \mu \mathrm{l}$ volume of either C. albicans $\left(5 \times 10^{5}\right.$ cells) or $S$. aureus [clinical isolate grown in nutrient broth (Oxoid) at $37^{\circ} \mathrm{C}$ and 200 r.p.m. to early stationary phase]. A culture of $S$. aureus with an $\mathrm{OD}_{600}$ value of 1 was diluted 1 in 4 in PBS for the inoculation. Infected larvae were placed at $30{ }^{\circ} \mathrm{C}$ and survival was monitored over $72 \mathrm{~h}$.

Determination of the haemocyte density of G. mellonella. G. mellonella larvae were injected with PBS or caspofungin as above, placed at $30{ }^{\circ} \mathrm{C}$, and the haemocyte density was determined after 4 and $24 \mathrm{~h}$. Haemocyte density was ascertained by collecting the haemolymph in a pre-chilled $1 \mathrm{ml}$ tube containing a few grains of 1-phenyl-3-(2-thiazolyl)-2-thiourea (Sigma-Aldrich) to prevent melanization. Haemolymph was diluted 1 in 10 in cold PBS containing $0.37 \%(\mathrm{v} / \mathrm{v})$ 2-mercaptoethanol (Sigma-Aldrich) to reduce clotting and melanization. Haemocytes were counted on a haemocytometer and the density (ml haemolymph $)^{-1}$ was calculated.

RNA extraction from G. mellonella. Larvae were inoculated with PBS or caspofungin $\left(0.19,0.095\right.$ or $\left.0.0475 \mu \mathrm{g} \mathrm{ml}^{-1}\right)$ and incubated at $30{ }^{\circ} \mathrm{C}$ for $4 \mathrm{~h}$. Three larvae per treatment were selected, and crushed using liquid nitrogen and a sterile pestle and mortar. To this, $3 \mathrm{ml}$ TRI-reagent (Sigma-Aldrich) was added, mixed and left at room temperature for $15 \mathrm{~min}$. The mixture was placed in sterile $1.5 \mathrm{ml}$ tubes and centrifuged at $12000 \mathrm{~g}$ for $10 \mathrm{~min}$ at $4{ }^{\circ} \mathrm{C}$ (Eppendorf centrifuge 5417R). The pellets were discarded and the supernatants collected. Chloroform $(200 \mu \mathrm{l})$ (molecular grade; Sigma-Aldrich) was added and mixed vigorously by vortexing. The solution was allowed to stand at room temperature for $10 \mathrm{~min}$ and centrifuged at $12000 \mathrm{~g}$ for $10 \mathrm{~min}$ at $4{ }^{\circ} \mathrm{C}$. The top layer was collected, placed in a tube and $500 \mu$ 2-propanol (molecular grade; Sigma-Aldrich) was added. The tube was inverted several times, left to stand for $10 \mathrm{~min}$ and centrifuged at $12000 \mathrm{~g}$ for $10 \mathrm{~min}$ at $4{ }^{\circ} \mathrm{C}$. The supernatant was discarded and the resulting pellet was washed in $75 \%(\mathrm{v} / \mathrm{v})$ ethanol $(50 \mu \mathrm{l}$ molecular grade; Sigma-Aldrich $)$ and centrifuged at $12000 \mathrm{~g}$ for $10 \mathrm{~min}$ at $4{ }^{\circ} \mathrm{C}$. The supernatant was removed completely, and the resulting pellet was air-dried and resuspended in RNase-free water, dispensed into aliquots and stored at $-70{ }^{\circ} \mathrm{C}$ or used immediately.

cDNA synthesis and PCR analysis from G. mellonella RNA. Extracted RNA was DNase treated (DNase1; Sigma-Aldrich) prior to cDNA synthesis. cDNA synthesis was performed using a Superscript III first-strand synthesis system for RT-PCR kit from Invitrogen according to the manufacturer's instructions. Primers and cycle conditions were as used by Bergin et al. (2006). The housekeeping gene ACT1 (actin) was used as a control. PCR product $(4 \mu \mathrm{l})$ was visualized on a $1 \%(\mathrm{w} / \mathrm{v})$ agarose gel and images were analysed by densitometry to determine the relative fold increase/decrease by using the array analysis tool in the ImageQuantL software.

Effect of caspofungin on the haemolymph protein profile assessed by two-dimensional (2D) gel electrophoretic separation and liquid chromatography-mass spectrometry (LC-MS). Haemolymph was collected from larvae that had been injected $24 \mathrm{~h}$ previously with either PBS or caspofungin $(0.19 \mu \mathrm{g}$ $\left.\mathrm{ml}^{-1}\right)$, and the protein $(300 \mu \mathrm{g})$ was separated by $2 \mathrm{D}$ gel electrophoresis as described by Bergin et al. (2006). PBS-injected larvae were used as a control. Gel results were visualized using colloidal Coomassie staining. Gel images (in triplicate) were analysed by Progenesis SameSpots software (Nonlinear Dynamics) in order to assess the fold change between the control and caspofungin-injected larvae. Protein spots that displayed altered intensities between control and drug-treatment samples were excised, washed and trypsin digested as described by Shevchenko et al. (2006). Samples were analysed using a 6340 Ion Trap LC-MS spectrometer (Agilent Technologies) with BSA as external standards. The mass lists generated were BLAST searched using the Mascot MS/MS ion search program available at http://www.matrixscience.com. 
Statistical analysis. All experiments were performed on three independent occasions. The results presented are given as the mean \pm SE. A 2-tailed, 2-sample equal variance (homoscedastic) Student's $t$-test was performed and samples with a $P$ value $\leqslant 0.05$ were deemed significant.

\section{RESULTS}

\section{Analysis of the effect of caspofungin on the survival of G. mellonella infected with $C$. albicans prior to administration of the drug}

To establish the effectiveness of caspofungin in an insect model, larvae of G. mellonella were inoculated with $C$. albicans $\left(5 \times 10^{5}\right.$ cells per insect). After $1 \mathrm{~h}$, larvae were injected with caspofungin $\left(0.19,0.095\right.$ or $0.0475 \mu \mathrm{g} \mathrm{ml} l^{-1}$; $20 \mu \mathrm{l})$ or PBS $(20 \mu \mathrm{l})$ and incubated for up to $72 \mathrm{~h}$ at $30{ }^{\circ} \mathrm{C}$. Larvae that were injected with the given concentrations of caspofungin showed no ill-effects and there was no decrease in survival over $72 \mathrm{~h}$ (data not presented). Fig. 1 illustrates the effect of caspofungin on the survival of $G$. mellonella after inoculation with C. albicans. A statistically significant increase in survival at all time points was detected for $0.19 \mu \mathrm{g}$ caspofungin $\mathrm{ml}^{-1}$ treatment compared to the control. The survival rate increased from $66.6 \pm 8.8 \%$ in the control to $93.3 \pm 3.3 \%$ after $24 \mathrm{~h}$ with this concentration of caspofungin. After $72 \mathrm{~h}$, survival in the control larvae was $3.3 \pm 3.3 \%$ compared to $56.6 \pm 12.0 \%$ in larvae that had received caspofungin. Smaller increases in survival were observed using 0.095 and $0.0475 \mu \mathrm{g}$ caspofungin $\mathrm{ml}^{-1}$.

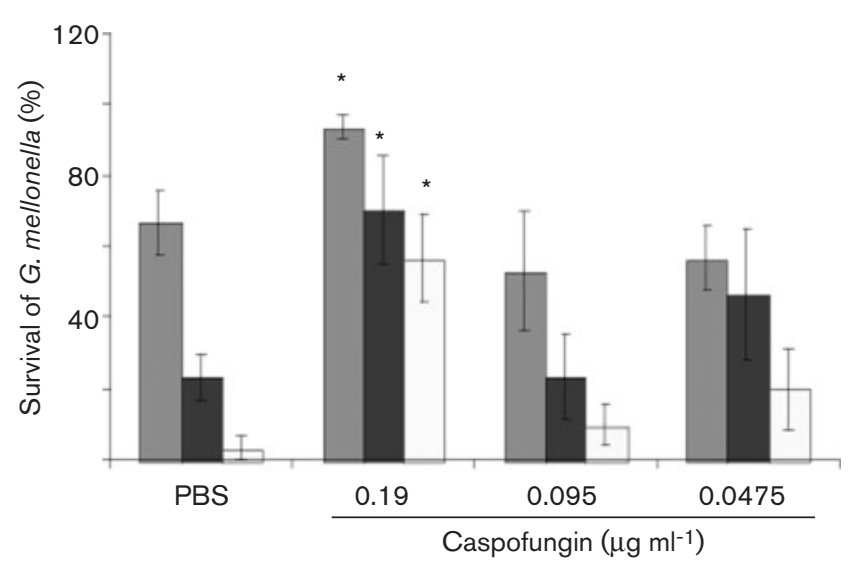

Fig. 1. Effect of caspofungin on the survival of G. mellonella inoculated with C. albicans. G. mellonella were inoculated with $C$. albicans $\left(5 \times 10^{5}\right.$ cells per larva) and subsequently $(1 \mathrm{~h})$ injected with PBS $(20 \mu \mathrm{l})$ or caspofungin $(20 \mu \mathrm{l} ; 0.19,0.095$ or $0.0475 \mu \mathrm{g}$ $\mathrm{ml}^{-1}$ ). Percentage survival was scored at 24,48 and $72 \mathrm{~h}$. The asterisks indicate a $P$ value $\leqslant 0.05$ relative to the PBS-injected control. Light grey bars, 24 h; dark grey bars, 48 h; white bars, $72 \mathrm{~h}$.

\section{Analysis of the effect of caspofungin on the survival of G. mellonella infected with $C$. albicans or $S$. aureus after administration of the drug}

Larvae of G. mellonella were injected with PBS or caspofungin, placed at $30{ }^{\circ} \mathrm{C}$ for $24 \mathrm{~h}$ and inoculated with $20 \mu \mathrm{l}$ of either C. albicans $\left(5 \times 10^{5}\right.$ cells) or S. aureus (a culture with an $\mathrm{OD}_{600}$ value of 1 was diluted 1 in 4 in PBS). Fig. 2(a) illustrates the effect of pre-injecting larvae with caspofungin $24 \mathrm{~h}$ before inoculating with C. albicans. A statistically significant increase in survival was observed after $48 \mathrm{~h}$ with all concentrations of caspofungin compared to the control. After $48 \mathrm{~h}$, survival increased from $43.3 \pm 3.3 \%$ in the control to $80 \pm 5.7 \%$ in $0.019 \mu \mathrm{g}$ caspofungin $\mathrm{ml}^{-1}$ injected larvae. A significant increase in survival was also observed after $72 \mathrm{~h}$ when 0.19 and $0.0475 \mu \mathrm{g}$ caspofungin $\mathrm{ml}^{-1}$ was administered.

Although caspofungin is a well established antifungal agent, we endeavoured to examine whether the immunomodulatory effect observed above was active against a
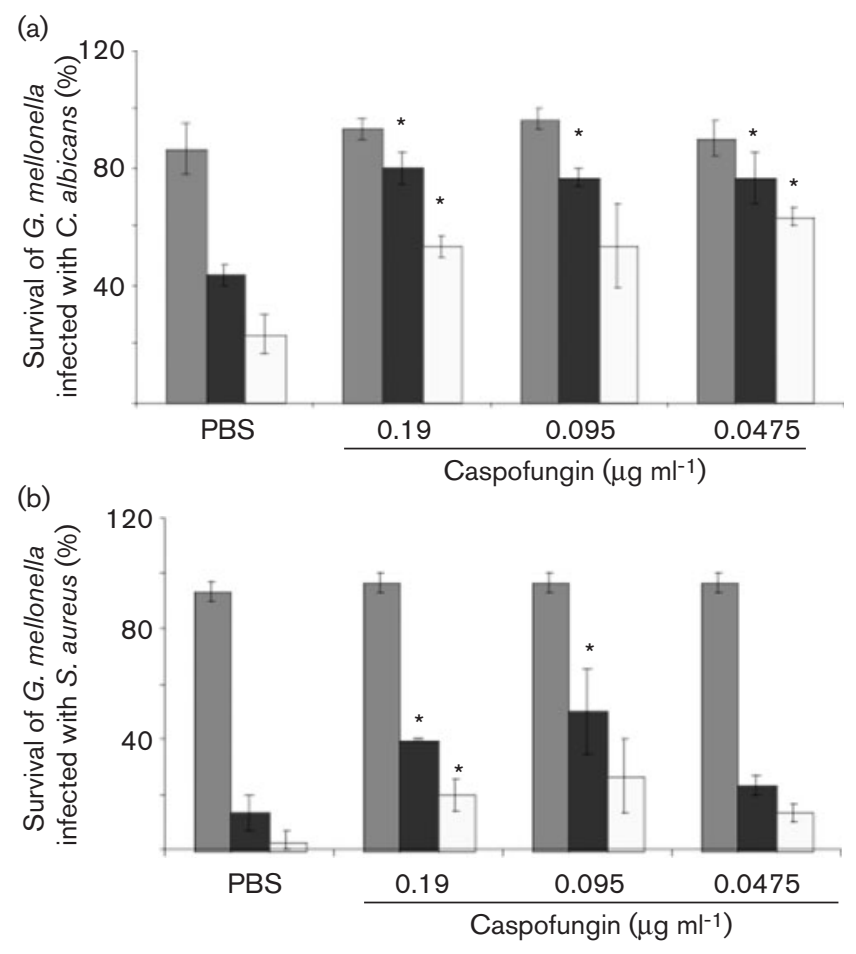

Fig. 2. Effect of caspofungin on the survival of G. mellonella inoculated with S. aureus or C. albicans. (a) G. mellonella were injected with caspofungin $24 \mathrm{~h}$ before injection with $C$. albicans $\left(5 \times 10^{5}\right.$ cells per larva). Larvae were placed at $30{ }^{\circ} \mathrm{C}$ and survival was monitored over $72 \mathrm{~h}$. (b) G. mellonella were injected with caspofungin $24 \mathrm{~h}$ before injection with $20 \mu \mathrm{l}$ S. aureus (a culture with an $\mathrm{OD}_{600}$ value of 1 was diluted 1 in 4 in PBS for use in the inoculation). Larvae were placed at $30{ }^{\circ} \mathrm{C}$ and survival was monitored over $72 \mathrm{~h}$. The asterisks indicate a $P$ value $\leqslant 0.05$ relative to the PBS-injected control. Light grey bars, $24 \mathrm{~h}$; dark grey bars, $48 \mathrm{~h}$; white bars, $72 \mathrm{~h}$. 
bacterial infection. Fig. 2(b) illustrates the effect of preinjecting larvae with caspofungin $24 \mathrm{~h}$ before infecting with $S$. aureus. It is evident that pre-injecting larvae with caspofungin resulted in a significant increase in survival of larvae compared to the control. For example, after $48 \mathrm{~h}$ larval survival was $13.3 \pm 6.6 \%$ in the control and $50 \pm 15.3 \%$ when larvae were administered $0.095 \mu \mathrm{g}$ caspofungin $\mathrm{ml}^{-1}$. Indeed, after $72 \mathrm{~h}$, survival of larvae increased from $3.3 \pm 3.3 \%$ in the control to $26.6 \pm 13.3 \%$ in those larvae injected with the same concentration of caspofungin. These data illustrate that pre-injecting larvae with caspofungin provides protection to subsequent fungal (C. albicans) or bacterial ( $S$. aureus) infection, indicating that survival is not due to the antifungal activity of caspofungin alone.

\section{Analysis of the effect of caspofungin on haemocyte densities in G. mellonella}

Administration of a foreign agent to an insect has the potential to evoke an antimicrobial immune response independent of whether the original agent has any inherent antimicrobial properties (Bergin et al., 2006; Mowlds et al., 2010). We investigated whether caspofungin altered the haemocyte density since this is an indication of larval susceptibility to infection (Bergin et al., 2003). Larvae were injected with caspofungin $\left(0.19,0.095\right.$ and $\left.0.0475 \mu \mathrm{g} \mathrm{ml}^{-1}\right)$ or PBS, and after 4 and $24 \mathrm{~h}$, haemocytes were extracted and counted using a haemocytometer. The result (Fig. 3) indicates that after $24 \mathrm{~h}$ incubation, caspofungin-treated larvae demonstrated an increase in haemocyte density. The haemocyte density was $1.7 \pm 0.1 \times 10^{6}$ haemocytes (ml haemolymph $)^{-1}$ in the control, $2.8 \pm 0.3 \times 10^{6}$ haemocytes $(\mathrm{ml} \text { haemolymph })^{-1}$ in larvae that had received a dose of $0.19 \mu \mathrm{g}$ caspofungin $\mathrm{ml}^{-1}, 3.1 \pm 0.4 \times 10^{6}$ haemocytes $(\mathrm{ml}$ haemolymph $)^{-1}$ in larvae that received a dose of $0.095 \mu \mathrm{g}$ caspofungin $\mathrm{ml}^{-1}$ and $2.8 \pm 0.5 \times 10^{6}$ haemocytes (ml haemolymph) ${ }^{-1}$ in larvae that received $0.0475 \mu \mathrm{g}$ caspofungin $\mathrm{ml}^{-1}$. These results suggest that administration of caspofungin to larvae induced an elevation in haemocyte density, which could contribute to the overall antimicrobial activity within the haemolymph.

\section{Analysis of the effect of caspofungin on the expression of antimicrobial genes in $\mathbf{G}$. mellonella}

It has been demonstrated previously that survival of larvae of G. mellonella following inoculation with C. albicans is mediated by an increase in the expression of AMP and immune protein-encoding genes (Bergin et al., 2006). The expression of the genes that encode transferrin (iron-binding protein; Yoshiga et al., 1997), galiomicin (defensin; Lee et al., 2004), IMPI (inducible metallo-proteinase inhibitor; Clermont et al., 2004) and gallerimycin (cysteine-rich antifungal peptide; Schuhmann et al., 2003) in G. mellonella in response to caspofungin administration was investigated. Expression of the IMPI-encoding gene increased to 206.1 \pm

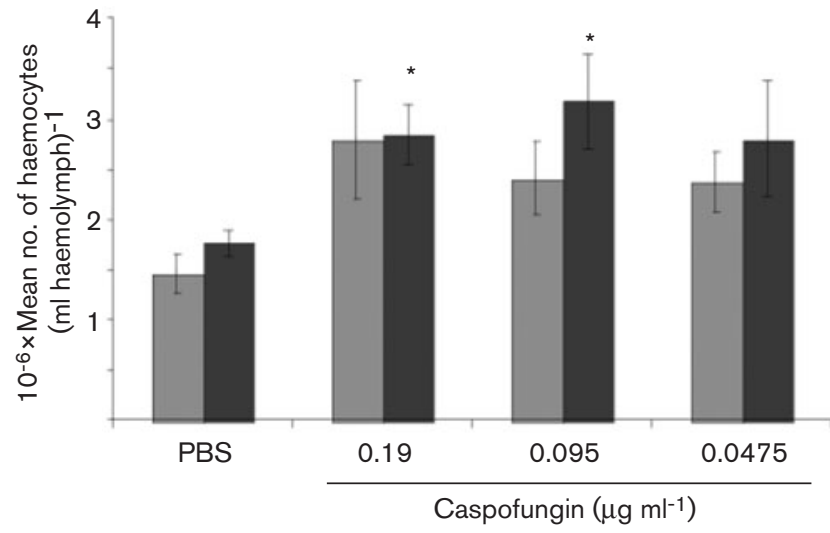

Fig. 3. Effect of caspofungin on the haemocyte density in G. mellonella. Haemocyte density in larvae of $G$. mellonella injected with PBS or caspofungin $\left(0.19,0.095\right.$ or $\left.0.0475 \mu \mathrm{g} \mathrm{ml}^{-1}\right)$ was assessed after 4 and $24 \mathrm{~h}$. The asterisks indicate a $P$ value $\leqslant 0.05$ relative to the PBS-injected control. Light grey bars, $4 \mathrm{~h}$; dark grey bars, $24 \mathrm{~h}$.

$26.1 \%$ relative to the control when $0.095 \mu \mathrm{g}$ caspofungin $\mathrm{ml}^{-1}$ was used (Fig. 4). In the case of the transferrin-encoding gene, the greatest increase in expression was noted at a concentration of $0.19 \mu \mathrm{g}$ caspofungin $\mathrm{ml}^{-1}$, which gave a relative value of $208.6 \pm 6.7 \%$. Smaller increases were observed at the other concentrations of drug used $(133.3 \pm 19.9$ and $128.7 \pm 4.2 \%$ at 0.095 and $0.0475 \mu \mathrm{g} \mathrm{ml}^{-1}$, respectively). Expression of the galiomicin-encoding gene showed small increases over the different concentrations resulting in increases to $122.1 \pm 3.6$, $130.4 \pm 10.4$ and $119.0 \pm 16.0 \%$ at $0.19,0.095$ and $0.0475 \mu \mathrm{g}$ caspofungin $\mathrm{ml}^{-1}$, respectively. The gallerimycin-encoding gene demonstrated the smallest alteration in expression following exposure to the drug.

\section{Assessment of the effect of caspofungin on the expression of larval proteins}

Larvae were injected with $0.019 \mu \mathrm{g}$ caspofungin $\mathrm{ml}^{-1}$ and after $24 \mathrm{~h}$, haemolymph protein was extracted and resolved by $2 \mathrm{D}$ electrophoresis in order to determine changes in the protein profile. Spots of interest were excised from 2D gels (Fig. 5) and trypsin-digested prior to identification by LC-MS (Table 1). A number of spots showing homology to proteins with immune function or involved in regulating metabolism were found to be altered in expression. The $32 \mathrm{kDa}$ ferritin subunit I and II (spots 3 and 4) were shown to have increased by 2 and 1.6-fold, respectively, following caspofungin administration. Ferritin is important in iron binding, and storage and maintaining cellular iron homeostasis, along with playing a role in the immune response (Levy et al., 2004). Recent research has demonstrated increased expression of this protein in larvae in response to mercury (Choi et al., 2006). Spot 6 showed homology to prophenoloxidase, 
(a)

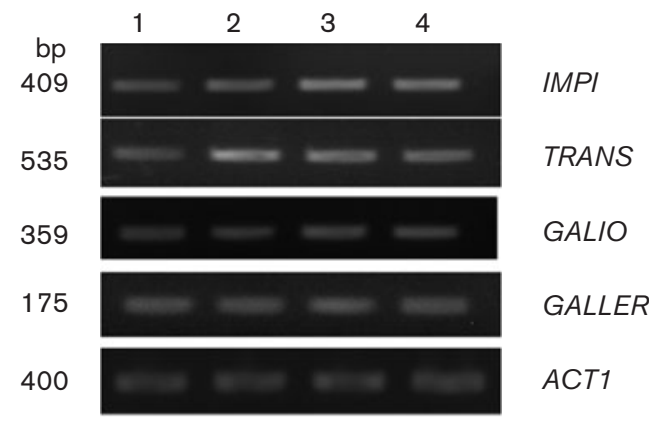

(b)

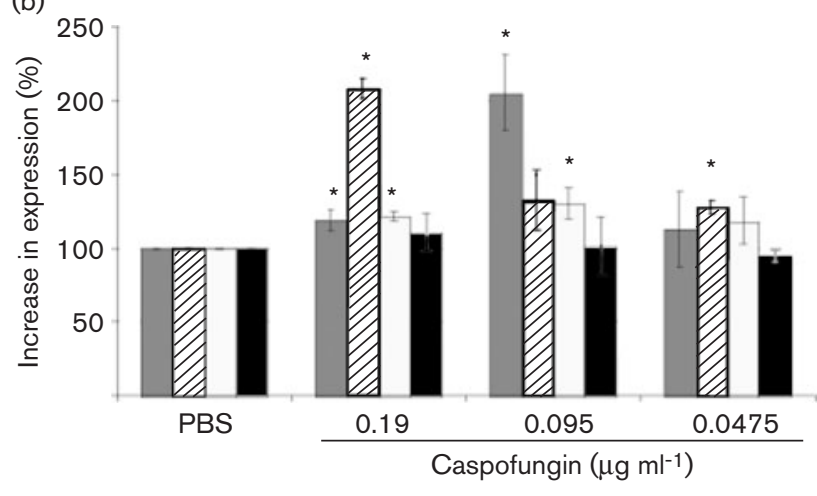

Fig. 4. Relative expression of four genes involved in the immune response of G. mellonella and a housekeeping gene. (a) Visualization of PCR products on a $1 \%(\mathrm{w} / \mathrm{v})$ agarose gel. RTPCR was performed as described in Methods. Lane: 1, PBS; 2 , $0.19 \mu \mathrm{g}$ caspofungin $\mathrm{ml}^{-1} ; 3,0.095 \mu \mathrm{g}$ caspofungin $\mathrm{ml}^{-1} ; 4$, $0.0475 \mu \mathrm{g}$ caspofungin $\mathrm{ml}^{-1}$. (b) Densitometric quantification of the PCR products normalized to the values of the ACT1 control. The asterisks indicate a $P$ value $\leqslant 0.05$ relative to the PBSinjected control. Light grey bars, IMPI-encoding gene; hatched bars, transferrin-encoding gene; white bars, galiomicin-encoding gene; black bars, gallerimycin-encoding gene.

which is a protein involved in melanin synthesis, a key defence against pathogens (Kavanagh \& Reeves, 2004). Prophenoloxidase is found in the haemocyte as the inactive form of phenoloxidase, which catalyses the formation of melanin. Administration of caspofungin to G. mellonella resulted in a 1.9-fold increase in expression. Spot 8 showed homology to juvenile hormone binding protein (JHBP), which is an important regulator of growth, development and reproduction in insects. JHBP carries juvenile hormone $(\mathrm{JH})$ to the target tissues and protects it from digestion by non-specific esterases (Sanburg et al., 1975; Kramer \& Childs, 1977). Here it was shown that this protein was increased by 1.2 -fold upon caspofungin treatment of larvae. Spot 7 showed homology to arginine kinase, which is a kinase involved in the transfer of a phosphate from ATP, and the protein was observed to have increased by 2.2 -fold when larvae were injected with caspofungin. These results demonstrate that upon administration of caspofungin there is an increase in the expression of some proteins with antimicrobial functions or with metabolic activity.

\section{DISCUSSION}

Conventional assays to examine the virulence of various microbial pathogens have traditionally relied upon the use of vertebrate species. In recent years it has been demonstrated that insects may be employed to evaluate the virulence of fungi (Cotter et al., 2000; Reeves et al., 2004; Lionakis \& Kontoyiannis, 2005; Mylonakis et al., 2005), bacteria (Mansfield et al., 2003) and parasites (Boulanger et al., 2001), and may be employed for the in vivo screening of antimicrobial drugs (Hamamoto et al., 2004, 2009; Johny et al., 2007). The immune response of insects is similar to the innate immune response of mammals (Kavanagh \& Reeves, 2004), and contains structural and passive barriers, as well as cellular and humoral responses mediated by haemocytes and the fat body within the haemolymph. As a consequence of these similarities there is a strong correlation between the virulence of various pathogens when tested in insects and in mice (Brennan et al., 2002; Jander et al., 2000).

Caspofungin demonstrates potent in vivo antifungal activity (Petraitiene et al., 2002) and an excellent safety profile with patients suffering few adverse effects (Maertens et al., 2004; Walsh et al., 2004). In this work it was demonstrated that injection of larvae with caspofungin following inoculation with $C$. albicans resulted in statistically significant increases in survival. Similarly, it was demonstrated that injection of caspofungin before infecting with a fungal or bacterial pathogen significantly increases the survival rate. Interestingly, administration of caspofungin can provide protection against both a fungal (C. albicans) and a bacterial (S. aureus) infection indicating that, in addition to the inherent antifungal activity of the drug, caspofungin administration also induces a nonspecific antimicrobial response in larvae.

Haemocytes are similar to the phagocytes of mammals (Bergin et al., 2005) and the majority circulate freely in the haemolymph, but a significant number can be found associated with internal organs such as the fat body, trachea or digestive system (Ratcliffe, 1985). There are six types of haemocytes, and some are involved in phagocytosis and encapsulization, which are important in the insect cellular defence against microbes (Tojo et al., 2000). The administration of caspofungin to G. mellonella larvae caused an increase in haemocyte density after $4 \mathrm{~h}$ and this increase was also evident after $24 \mathrm{~h}$, which may be due to the release of haemocytes from the associated organs and/ or the proliferation of haemocytes. The ability of caspofungin-treated larvae to survive a fungal or bacterial infection could be due, in part, to the elevation in the haemocyte density evident in such larvae.

G. mellonella can synthesize a number of AMPs that are released into the haemolymph where they can attack invading microbes (Kavanagh \& Reeves, 2004). It was observed that the expression of the gene encoding transferrin was upregulated approximately twofold when larvae were injected with $0.19 \mu \mathrm{g}$ caspofungin $\mathrm{ml}^{-1}$. Interestingly, the 

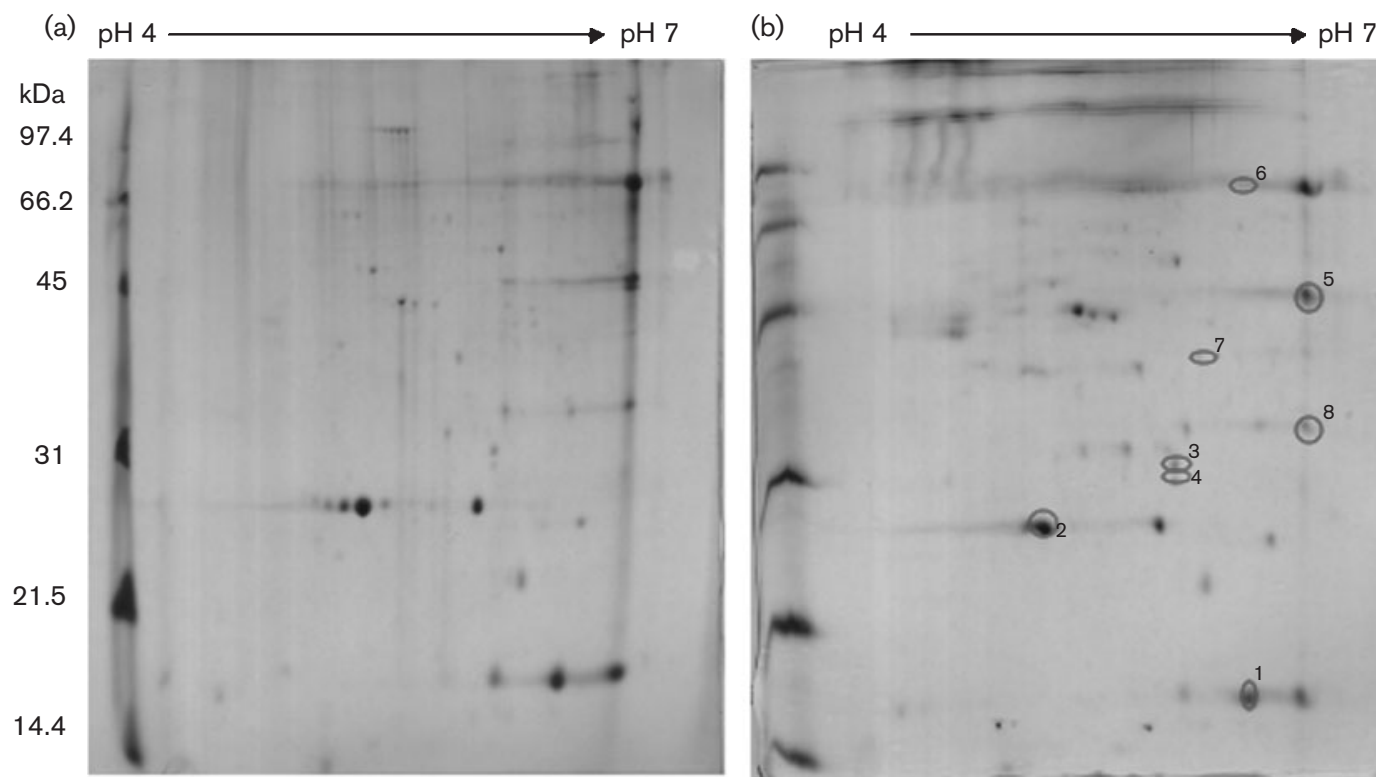

Fig. 5. 2D gels of G. mellonella haemolymph protein showing spots chosen for identification by LC-MS. (a) Haemolymph protein separated from PBS-injected larvae. (b) Haemolymph protein separated from $\left(0.19 \mu \mathrm{g} \mathrm{ml}^{-1}\right)$ caspofungin-injected larvae. Spots 1-8 were excised for identification by LC-MS. The gel images are representative images of experiments performed in triplicate.

Table 1. G. mellonella protein spots identified by LC-MS plus fold changes in expression in response to caspofungin

Spots were removed, trypsin-digested and analysed by LC-MS as described in Methods. Images were analysed with Progenesis SameSpots software to assess the fold change in expression.

\begin{tabular}{|c|c|c|c|c|c|c|}
\hline Protein & $\begin{array}{l}\text { Spot } \\
\text { no. }\end{array}$ & $\begin{array}{l}\text { Fold change upon } \\
\text { injection of } 0.19 \mu \mathrm{g} \\
\text { caspofungin } \mathrm{ml}^{-1} \\
\text { (compared to } \\
\text { control) }\end{array}$ & Mascot score & $\begin{array}{c}\text { Coverage } \\
(\%)\end{array}$ & $\begin{array}{c}\text { UniProtKB } \\
\text { accession no. }\end{array}$ & Function \\
\hline Apolipophorin III & 1 & - & 459 & 44 & P80703 & $\begin{array}{l}\text { Antimicrobial; antibiotic; induced by } \\
\text { bacterial infection; immune response; } \\
\text { transport of lipids }\end{array}$ \\
\hline $\begin{array}{l}27 \mathrm{kDa} \\
\text { haemolymph } \\
\text { protein }\end{array}$ & 2 & +1.2 & 552 & 49 & P83632 & Secreted; signal; extracellular region \\
\hline $\begin{array}{l}32 \mathrm{kDa} \text { ferritin } \\
\text { subunit I }\end{array}$ & 3 & +2 & 329 & 20 & Q8WSA5 & $\begin{array}{l}\text { Ferric iron binding and transport; } \\
\text { oxidoreductase activity }\end{array}$ \\
\hline $\begin{array}{l}32 \mathrm{kDa} \text { ferritin } \\
\text { subunit II }\end{array}$ & 4 & +1.6 & 314 & 20 & & \\
\hline $\begin{array}{l}\text { Transferrin } \\
\text { precursor }\end{array}$ & 5 & -1.2 & 609 & 21 & Q6UQ29 & $\begin{array}{l}\text { Cellular iron ion homeostasis and } \\
\text { transport; extracellular region; ferric } \\
\text { iron binding }\end{array}$ \\
\hline $\begin{array}{l}\text { Prophenoloxidase } \\
\text { subunit II }\end{array}$ & 6 & +1.9 & 393 & 10 & Q6UEH6 & $\begin{array}{l}\text { Transport; oxygen transporter activity; } \\
\text { oxidoreductase activity }\end{array}$ \\
\hline Arginine kinase & 7 & +2.2 & 201 & 19 & B3TG12 & Transferase, kinase activity \\
\hline JHBP & 8 & +1.2 & 182 & 20 & Q8ITP4 & $\begin{array}{l}\mathrm{JH} \text { regulates embryogenesis and } \\
\text { stimulates reproductive maturation in } \\
\text { the adult; JHBP protects JH molecules } \\
\text { from hydrolysis by non-specific } \\
\text { esterases }\end{array}$ \\
\hline
\end{tabular}


protein transferrin precursor (spot 5 in Fig. 5) was observed to have a fold change of -1.2 when larvae were injected with caspofungin. A possible reason for this difference may be due to the time at which the larvae were sampled after administration of the drug (gene expression after $4 \mathrm{~h}$, protein analysis after $24 \mathrm{~h}$ ). The levels of transferrin in $G$. mellonella may initially rise upon caspofungin injection, but may decrease after several hours. Expression of IMPI was also increased approximately twofold following caspofungin treatment $\left(0.095 \mu \mathrm{g} \mathrm{ml}^{-1}\right)$. Smaller increases were observed for galiomicin and gallerimycin following administration of the agent. These results suggest that while caspofungin may not induce the expression of a wide range of AMPs it may activate a selected subset of proteins involved in the immune response (i.e. transferrin and IMPI). This phenomenon has been observed previously where physical stress induced the expression of a selected number of AMPs in G. mellonella (Mowlds et al., 2008). Analysis of the proteome of larvae that had received caspofungin $24 \mathrm{~h}$ previously revealed the increased expression of a number of peptides that show homology to proteins that exhibit immune properties (e.g. prophenoloxidase, ferritin), and those involved with growth and development (arginine kinase, JHBP).

An increase in AMP or immune protein gene expression and haemocyte density in G. mellonella following caspofungin treatment may indicate a novel means of protection against infection. It appears that not only can caspofungin kill fungal cells in vivo, but also it may enhance the insect's natural defences against infection. The injection of non-self material into the haemocoel of G. mellonella larvae can prime the immune response against a subsequent microbial challenge although the original material may have no inherent antimicrobial properties (Bergin et al., 2006; Mowlds et al., 2010). Administration of mercury to larvae also resulted in an increase in the expression of ferritin, which has a role in the insect's immune response (Choi et al., 2006). The ability of caspofungin to stimulate the larval immune response is an added benefit in that it constitutes a second line of attack against the invading pathogen.

While the utility of employing insects to assess the virulence of microbial pathogens or examine the in vivo properties of antimicrobial agents is now well established, researchers should be aware that, in addition to the inherent antimicrobial activity of the test agent, administration of the agent to larvae can trigger an increase in the insect's immune response. Controls to allow discrimination between the antimicrobial properties of a novel agent and the alteration in the immune response of insects induced by the agent should be included in all experiments to ensure that the efficacy of the antimicrobial agent, rather than its immune priming abilities, is measured.

\section{ACKNOWLEDGEMENTS}

This work was supported by funding from the Higher Education Authority of Ireland through the Programme for Research in Third Level Institutes, cycles 3 and 4.

\section{REFERENCES}

Bergin, D., Brennan, M. \& Kavanagh, K. (2003). Fluctuations in haemocyte density and microbial load may be used as indicators of fungal pathogenicity in larvae of Galleria mellonella. Microbes Infect $\mathbf{5}$, 1389-1395.

Bergin, D., Reeves, E. P., Renwick, J., Wientjes, F. B. \& Kavanagh, K. (2005). Superoxide production in Galleria mellonella hemocytes: identification of proteins homologous to the NADPH oxidase complex of human neutrophils. Infect Immun 73, 4161-4170.

Bergin, D., Murphy, L., Keenan, J., Clynes, M. \& Kavanagh, K. (2006). Pre-exposure to yeast protects larvae of Galleria mellonella from a subsequent lethal infection by Candida albicans and is mediated by the increased expression of antimicrobial peptides. Microbes Infect $\mathbf{8}$, 2105-2112.

Boulanger, N., Ehret-Sabatier, L., Brun, R., Zachary, D., Bulet, P. \& Imler, J. L. (2001). Immune response of Drosophila melanogaster to infection with the flagellate parasite Crithidia spp. Insect Biochem Mol Biol 31, 129-137.

Brennan, M., Thomas, D. Y., Whiteway, M. \& Kavanagh, K. (2002). Correlation between virulence of Candida albicans mutants in mice and Galleria mellonella larvae. FEMS Immunol Med Microbiol 34, 153157.

Choi, C. W., Seo, D. H., Yuk, J. E., Park, J. B., Hwang, S. Y., Koh, S. K. \& Yun, C. Y. (2006). Upregulation of hemolymph and tissue ferritin by dietary $\mathrm{HgCl}_{2}$ in the wax moth Galleria mellonella. Entomol Res 36, 185-190.

Clermont, A., Wedde, M., Seitz, V., Podsiadlowski, L., Lenze, D., Hummel, M. \& Vilcinskas, A. (2004). Cloning and expression of an inhibitor of microbial metalloproteinases from insects contributing to innate immunity. Biochem J 382, 315-322.

Cotter, G., Doyle, S. \& Kavanagh, K. (2000). Development of an insect model for the in vivo pathogenicity testing of yeasts. FEMS Immunol Med Microbiol 27, 163-169.

Dunphy, G. B., Morton, D. B., Kropinski, A. \& Chadwick, J. M. (1986). Pathogenicity of lipopolysaccharide mutants of Pseudomonas aeruginosa for larvae of Galleria mellonella: bacterial properties associated with virulence. J Invertebr Pathol 47, 48-55.

Eggimann, P., Garbino, J. \& Pittet, D. (2003). Management of Candida species infections in critically ill patients. Lancet Infect Dis $\mathbf{3}$, 772-785.

Hamamoto, H., Kurokawa, K., Kaito, C., Kamura, K., Razanajatovo, I. M., Kusuhara, H., Santa, T. \& Sekimizu, K. (2004). Quantitative evaluation of the therapeutic effects of antibiotics using silkworms infected with human pathogenic microorganisms. Antimicrob Agents Chemother 48, 774-779.

Hamamoto, H., Tonoike, A., Narushima, K., Horie, R. \& Sekimizu, K. (2009). Silkworm as a model animal to evaluate drug candidate toxicity and metabolism. Comp Biochem Physiol C Toxicol Pharmacol 149, 334-339.

Jander, G., Rahme, L. \& Ausbel, F. (2000). Positive correlation between virulence of Pseudomonas aeruginosa mutants in mice and insects. J Bacteriol 182, 3843-3845.

Johny, S., Lange, C. E., Solter, L. F., Merisko, A. \& Whitman, D. W. (2007). New insect system for testing antibiotics. J Parasitol 93, 15051511.

Kartsonis, N. A., Nielsen, J. \& Douglas, C. M. (2003). Caspofungin: the first in a new class of antifungal agents. Drug Resist Updat 6, 197218.

Kavanagh, K. \& Reeves, E. P. (2004). Exploiting the potential of insects for in vivo pathogenicity testing of microbial pathogens. FEMS Microbiol Rev 28, 101-112. 
Kelly, J., Rowan, R., McCann, M. \& Kavanagh, K. (2009). Exposure to caspofungin activates Cap and Hog pathways in Candida albicans. Med Mycol 47, 697-706.

Kramer, K. J. \& Childs, C. N. (1977). Interaction of juvenile hormone with carrier proteins and hydrolases from insect haemolymph. Insect Biochem 7, 397-403.

Lavine, M. D. \& Strand, M. R. (2002). Insect haemocytes and their role in immunity. Insect Biochem Mol Biol 32, 1295-1309.

Lee, Y. S., Yun, E. K., Jang, W. S., Kim, I., Lee, J. H., Park, S. Y., Ryu, K. S., Seo, S. J., Kim, C. H. \& Lee, I. H. (2004). Purfication, cDNA cloning and expression of an insect defensin from the great wax moth, Galleria mellonella. Insect Mol Biol 13, 65-72.

Levy, F., Bulet, P. \& Ehret-Sabatier, L. (2004). Proteomic analysis of the systemic immune response of Drosophila. Mol Cell Proteomics 3, 156-166.

Lionakis, M. S. \& Kontoyiannis, D. P. (2005). Fruit flies as a minihost model for studying drug activity and virulence in Aspergillus. Med Mycol 43, S111-S114.

Maertens, J., Raad, I., Petrikkos, G., Boogaerts, M., Selleslag, D., Petersen, F. B., Sable, C. A., Kartsonis, N. A., Ngai, A. \& other authors (2004). Efficacy and safety of caspofungin for treatment of invasive aspergillosis in patients refractory to or intolerant of conventional antifungal therapy. Clin Infect Dis 39, 1563-1571.

Mansfield, B. E., Dionne, M. S., Schneider, D. S. \& Freitag, N. E. (2003). Exploration of host-pathogen interactions using Listeria monocytogenes and Drosophila melanogaster. Cell Microbiol 5, 901911.

Matha, V. \& Acek, Z. (1984). Changes in haemocyte counts in Galleria mellonella (L.) (Lepidoptera: Galleriidae) larvae infected with Steinernema sp. (Nematoda: Steinernematidae). Nematologica 30, 86-89.

Mowlds, P., Barron, A. \& Kavanagh, K. (2008). Physical stress primes the immune response of Galleria mellonella larvae to infection by Candida albicans. Microbes Infect 10, 628-634.

Mowlds, P., Coates, C., Renwick, J. \& Kavanagh, K. (2010). Dosedependent cellular and humoral responses in Galleria mellonella larvae following $\beta$-glucan inoculation. Microbes Infect 12, 146-153.

Mylonakis, E., Moreno, R., El Khoury, J. B., Idnurm, A., Heitman, J., Calderwood, S. B., Ausubel, F. M. \& Diener, A. (2005). Galleria mellonella as a model system to study Cryptococcus neoformans pathogenesis. Infect Immun 73, 3842-3850.
Petraitiene, R., Petraitis, V., Groll, A. H., Sein, T., Schaufele, R. L., Francesconi, A., Bacher, J., Avila, N. A. \& Walsh, T. J. (2002). Antifungal efficacy of caspofungin (MK-0991) in experimental pulmonary aspergillosis in persistently neutropenic rabbits: pharmacokinetics, drug disposition, and relationship to galactomannan antigenemia. Antimicrob Agents Chemother 46, 12-23.

Ratcliffe, N. A. (1985). Invertebrate immunity - a primer for the nonspecialist. Immunol Lett 10, 253-270.

Reeves, E. P., Messina, C. G. M., Doyle, S. \& Kavanagh, K. (2004). Correlation between gliotoxin production and virulence of Aspergillus fumigatus in Galleria mellonella. Mycopathologia 158, 73-79.

Rock, F. L., Hardiman, G., Timans, J. C., Kastelein, R. A. \& Bazan, J. F. (1998). A family of human receptors structurally related to Drosophila Toll. Proc Natl Acad Sci U S A 95, 588-593.

Sanburg, L. L., Kramer, K. J., Kezdy, F. J., Law, J. H. \& Oberlander, H. (1975). Role of juvenile hormone esterases and carrier proteins in insect development. Nature 253, 266-267.

Schuhmann, B., Seitz, V., Vilcinskas, A. \& Podsiadlowski, L. (2003). Cloning and expression of gallerimycin, an antifungal peptide expressed in immune response of greater wax moth larvae, Galleria mellonella. Arch Insect Biochem Physiol 53, 125-133.

Shevchenko, A., Tomas, H., Havlis, J., Olsen, J. V. \& Mann, M. (2006). In-gel digestion for mass spectrometric characterization of proteins and proteomes. Nat Protoc 1, 2856-2860.

Tojo, S., Naganuma, F., Arakawa, K. \& Yokoo, S. (2000). Involvement of both granular cells and plasmatocytes in phagocytic reactions in the greater wax moth Galleria mellonella. J Insect Physiol 46, 1129-1135.

Walsh, T. J., Teppler, H., Donowitz, G. R., Maertens, J. A., Baden, L. R., Dmoszynska, A., Cornely, O. A., Bourque, M. R., Lupinacci, R. J. \& other authors (2004). Caspofungin versus liposomal amphotericin $B$ for empirical antifungal therapy in patients with persistent fever and neutropenia. N Engl J Med 351, 1391-1402.

Wittwer, D., Franchini, A., Ottaviani, E. \& Wiesner, A. (1999). Presence of IL-1 and TNF like molecules in Galleria mellonella (Lepidoptera) haemocytes and in an insect cell line from Estimene acraea (Lepidoptera). Cytokine 11, 637-642.

Yoshiga, T., Hernandez, V. P., Fallon, A. M. \& Law, J. H. (1997). Mosquito transferrin, an acute-phase protein that is up-regulated upon infection. Proc Natl Acad Sci U S A 94, 12337-12342.

Zhao, L. \& Kanost, M. R. (1996). In search of a function for hemolin, a haemolymph protein from the immunoglobulin superfamily. J Insect Physiol 42, 73-79. 